\title{
Hydrogeophysics Exploration Approximately Ain Al Atti (Region of Southeast Erfoud Morocco)
}

\author{
${ }^{1}$ Dakir Ibrahim, ${ }^{2}$ Benamara Ahmed, ${ }^{1}$ Aassoumi Habiba, \\ ${ }^{3}$ Ouallali Abdessalam and ${ }^{4}$ Ait Bahammou Youssef \\ ${ }^{1}$ Laboratory of Environmental Geology and Natural Resources, Cartography and Digital Technologies Team, \\ Department of Geology, Faculty of Science, Abdelmalek Essaadi University, Tetouan. Morocco \\ ${ }^{2}$ Laboratory of Applied Geophysics and Modeling in Geoenvironment, Department of Geology, \\ National School of Arts and Crafts, Moulay Ismail University 50500 Meknes, Morocco \\ ${ }^{3}$ Laboratory of Engineering and Environment, Faculty of Sciences and Technics, \\ Hassan II University.28810, Mohammadia, Morocco \\ ${ }^{4}$ Laboratory of Geophysics and Natural Risks, Department of Geology, Mohammed V University, \\ Faculty of Sciences, Rabat, Morocco
}

\author{
Article history \\ Received: 11-09-2020 \\ Revised: 12-12-2020 \\ Accepted: 16-12-2020 \\ Corresponding Author: \\ Dakir Ibrahim \\ Laboratory of Environmental \\ Geology and Natural Resources, \\ Cartography and Digital \\ Technologies Team, \\ Department of Geology, Faculty \\ of Science, Abdelmalek Essaadi \\ University, Tetouan. Morocco \\ Email: dakiribrahim@gmail_com
}

\begin{abstract}
Electrical resistivity and Very Low Frequency electromagnetic profiles (VLF) were introduced for a litho-structural study in the locality of Douira, located in the Errachidia basin. The electrical reading was carried out with a Schlemberger type device. The VLF profiles were implemented with a different length reaching $1600 \mathrm{~m}$ and profile lines oriented in the direction NNW-SSE and N-S. The VLF measurements were obtained using an Iris T-VLF instrument and the data filtering was carried out using the KHFFILT software. The Karous-Hjelt filter was applied to the real component of the secondary electromagnetic field. The qualitative interpretation of the resistivity results has shown that the formations identified in the locality of Douira are more resistant than those encountered around Ain Al Atti, this difference is the salinity coming from marly formations with intercalation of gypsum deep in the vicinity by Ain Al Atti. The semiquantitative interpretation of the VLF results showed the presence of a main fracture zone, oriented NW-SE, which feeds the Ain Al Atti source.
\end{abstract}

Keywords: Errachidia Basin, Electrical Survey, Fracture Zone, VLF-EM, Resistivity, Filtering KH, Groundwater Exploration

\section{Introduction}

In Morocco, the continual decrease in water resources is the current major problem, since water is a determining factor for sustainable development and improving the quality of life. The quantitative and qualitative management of groundwater and surface water resources is currently a necessity, given the continuous increase in water demand, on the one hand and the degradation of water quality observed during the past few years on the other hand. Water resources are limited and drought affects most of the country and becomes seriously threatening.

In the south-east of Morocco, or more precisely in the province of Errachidia, the scarcity and randomness of precipitation, the increasingly worrying desertification, the overexploitation of groundwater, linked to the strong demographic pressure and agriculture and animal husbandry activities have a great influence on the piezometric levels of groundwater (Amharref, 1991). The salt water from the source of Ain Al Atti has a negative impact on the environment by inducing direct chemical contamination on the aquifers in place. This therefore requires urgent intervention to curb the polluting flow from this source (Ammary, 2007). The problem addressed by this study concerns the potential groundwater in the locality of Douira north of the Ain $\mathrm{Al}$ Atti source. This article helps assess this potential by identifying fracturing zones. Faults represent a special target for hydrogeological exploration and can play an important role in the supply of groundwater (Reinhard, 2006). To achieve the objective of this article to highlight the litho-structural parameters, the working procedure will be based on electrical soundings, in order to determine the vertical variation of the resistivity obtained at the level of Douira and at the level of Ain Al 
Atti. On the other hand, it will be based on the Very Low Frequency Electromagnetic technique (VLF-EM) in order to locate the alignment of the fractured areas.

\section{Geography and Geological Setting}

The study area is located about $50 \mathrm{~km}$ south of Errachidia and $20 \mathrm{~km}$ north of Erfoud Fig. 1. It is a part of cretaceous basin of Errachidia (South-eastern Morocco). This basin is characterized by a stratigraphic series that ranges from paleozoic to quaternary. In the outcrop Fig. 2, the basin is generally composed of carbonate deposits of Turonian (Choubert and Faure-Muret, 1960), sandstone and sand with gypsum intercalation attributed to Infracenomanian and sand clay with gypsum and anhydrite of Senonian (Choubert, 1948). Locally, from drilling data, the Infracenomanian deposits overlie the Paleozoic (angular discordance). The quaternary is presented by alluvium and conglomerates. It shows varying thickness layers between 5 and $40 \mathrm{~m}$ (Amharref, 1991).

\section{Lithostratigraphy}

The stratigraphic $\log$ in Fig. 3 shows the formations constituting the basin range from the Paleozoic to the Quaternary.

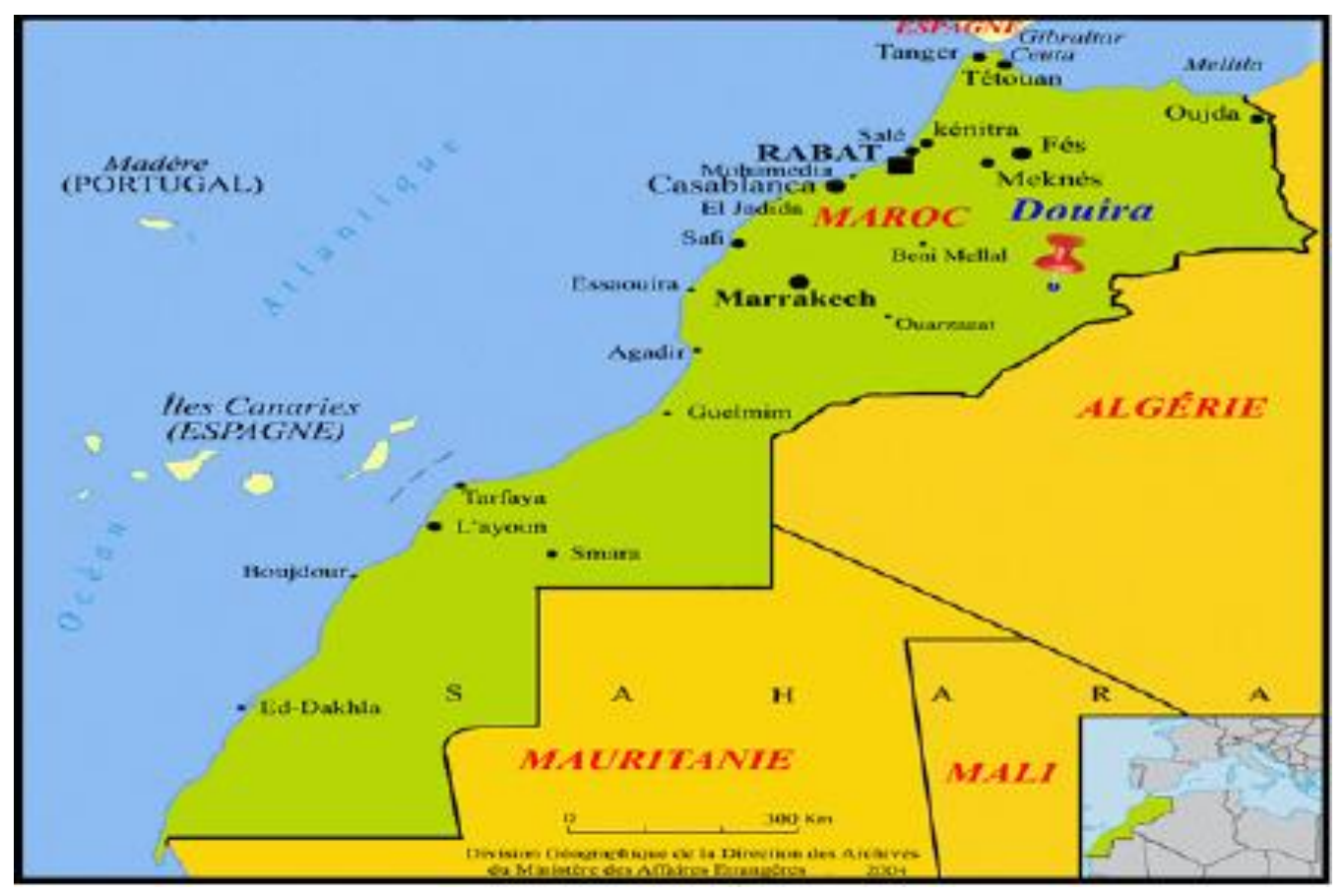

Fig. 1: Geographic situation of the study area

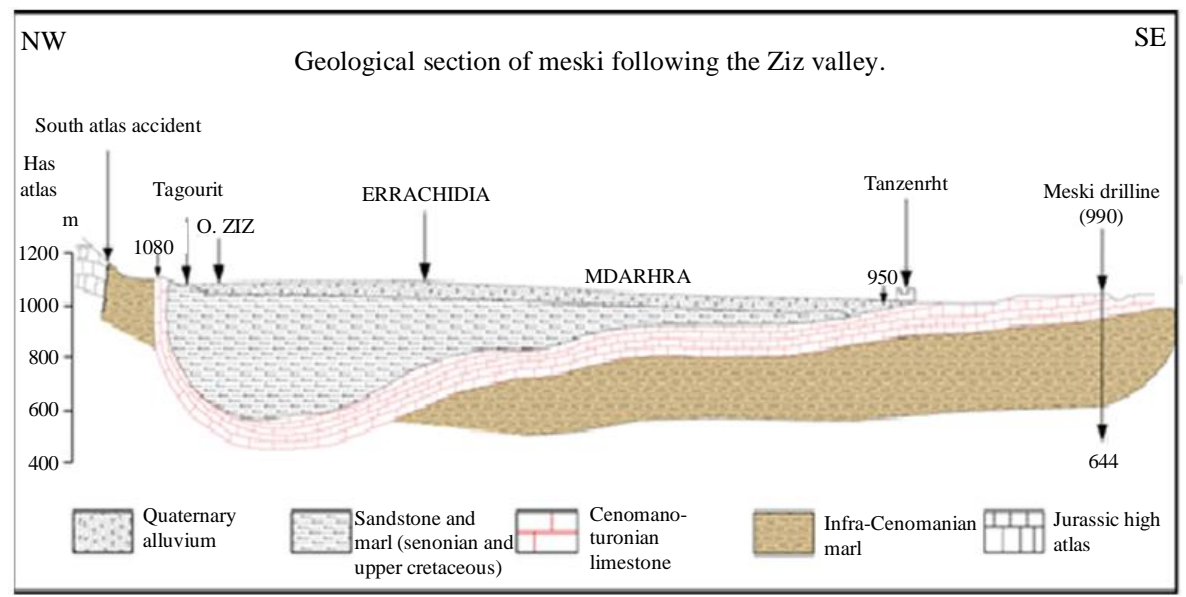

Fig. 2: Geological section of the Errachidia basin by (Margat, 1977) 


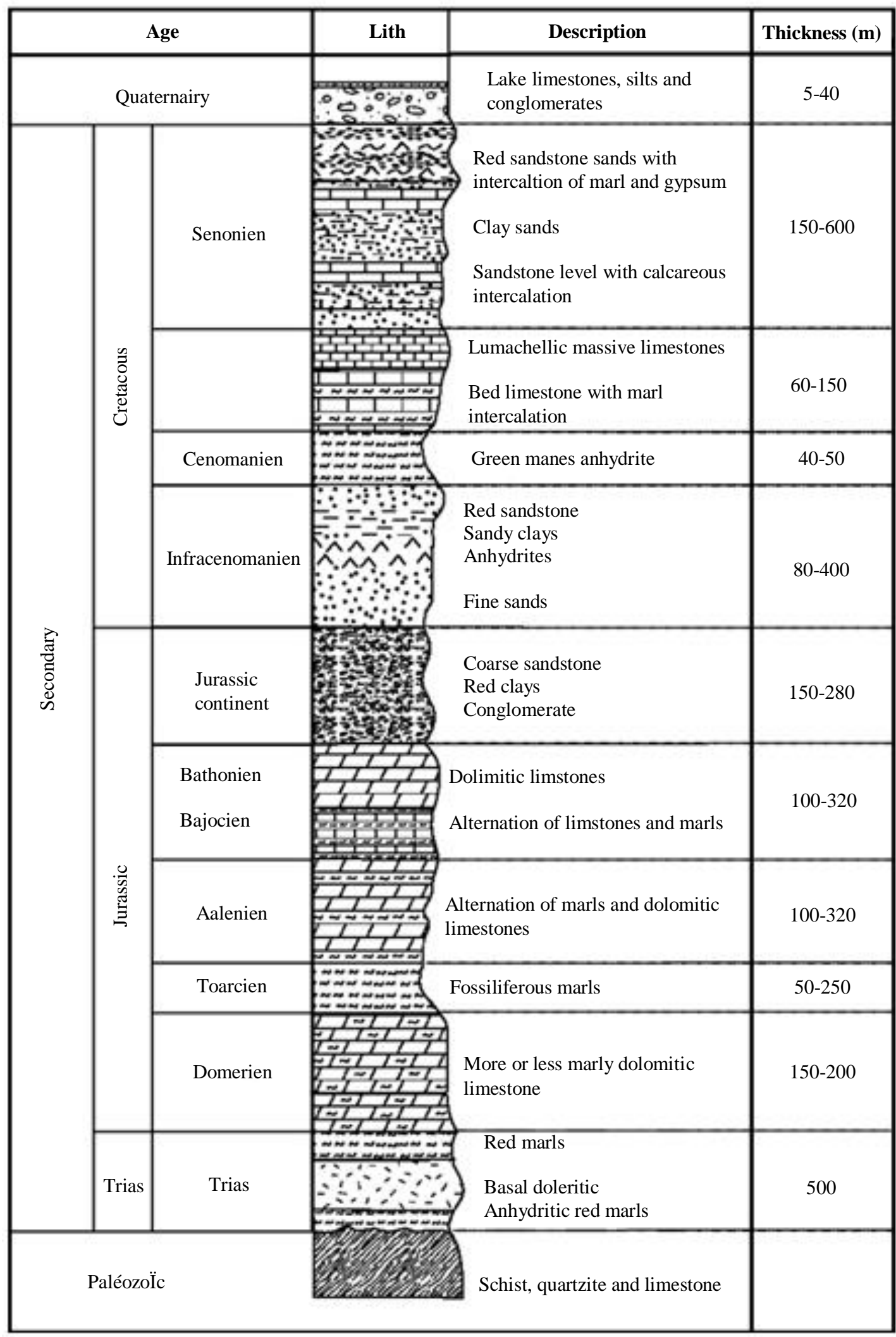

Fig. 3: Synthetic stratigraphic log of the Cretaceous basin of Errachidia (Amharref, 1991) 


\section{Materials and Methods}

\section{Electrical Survey}

The electrical sounding consists of the analysis of the apparent resistivity of the subsoil, measured by a symmetrical quadrupole device (AMNB) for a succession of spacing of the electrodes $A B$. The investigation depth is adjusted by varying the distance between the current injection electrodes $A$ and $B$. The difference in the potential measured between $M$ and $N$ reflects an apparent resistivity linked to the true resistivity and to the thicknesses of all the layers interested in the AMNB device. This method is widely used and generally provides a good initial approach Fig. 4. The apparent resistivity $\rho_{a}$ is calculated from the current I and the potential difference $\Delta V$ (Equation 1). The coefficient $K$ is called geometric factor. For Schlemberger configuration, the factor $K$ can be calculated from the electrode spacing by (Equation 2):

$$
\rho_{2}=K \cdot \frac{\Delta V_{M N}}{I_{A B}}
$$

$$
K=2 \pi a
$$

\section{VLF Electromagnetic Survey}

The Very Low Frequency Electromagnetic (VLF-EM) is based on the use of radio waves in the range of 15 to $30 \mathrm{kHz}$. The signal primary magnetic field $\left(H_{p}\right)$ emitted by the VLF stations, can be captured in the field by the VLF instruments. When a conductor (e.g., a fracture zone) is crossed by the $H_{p}$ electromagnetic field, an induced current (Current of Foucault) flows through it and produces a secondary magnetic field $\left(H_{s}\right)$ out-ofphase with primary magnetic field oriented in any direction (McNeill and Labson, 1991). In this case the conductive body acts as a second source (Kaya et al., 2007). The resulting field from the sum of primary magnetic field and secondary magnetic field is elliptically polarized. This ellipse of polarisation has two components with the same frequency, but different amplitude and phase, (Eze et al., 2004). The in-phase $H_{p}$ is the Real component $\left(R_{e}\right)$ proportional to the tilt $\tau$ (inclination of the major axis of the ellipse), while the out of phase $H p$ is the Imaginary component (Im) proportional to the ellipticity $\varepsilon$ (the ratio between the minor and the major axis b/a). These two components $\tau$ and $\varepsilon$ are described by the Equations (3 and 4) below (Saydam, 1981):

$$
\begin{aligned}
& \tau=R_{e} / H_{p} \\
& \varepsilon=I_{m} / H_{p}
\end{aligned}
$$

During our study, the survey was carried out using the Receiver T-VLF Iris Instruments, operating in tilt angle mode, in order to measure the parameters of the ellipse of polarization, which are the tilt $\tau$ and the ellipticity $\varepsilon$ Fig. 5. In this mode, it is convenient to operate with a transmitter (VLF station) which is located in the supposed strike $\left( \pm 45^{\circ}\right)$ of the prospected target for a maximum coupling. For detecting the supposed fractures in the study area, the GBR station located in Rugby (England) has been chosen, with a power of $750 \mathrm{KW}$, which emits a signal with a frequency of 16 $\mathrm{KHz}$. On the fieldwork, 6 VLF EM profiles were conducted, with profile length reaches $1600 \mathrm{~m}$. Readings were taken respecting a spacing of $20 \mathrm{~m}$. The profiles lines were oriented NNW-SSE and N-S directions.

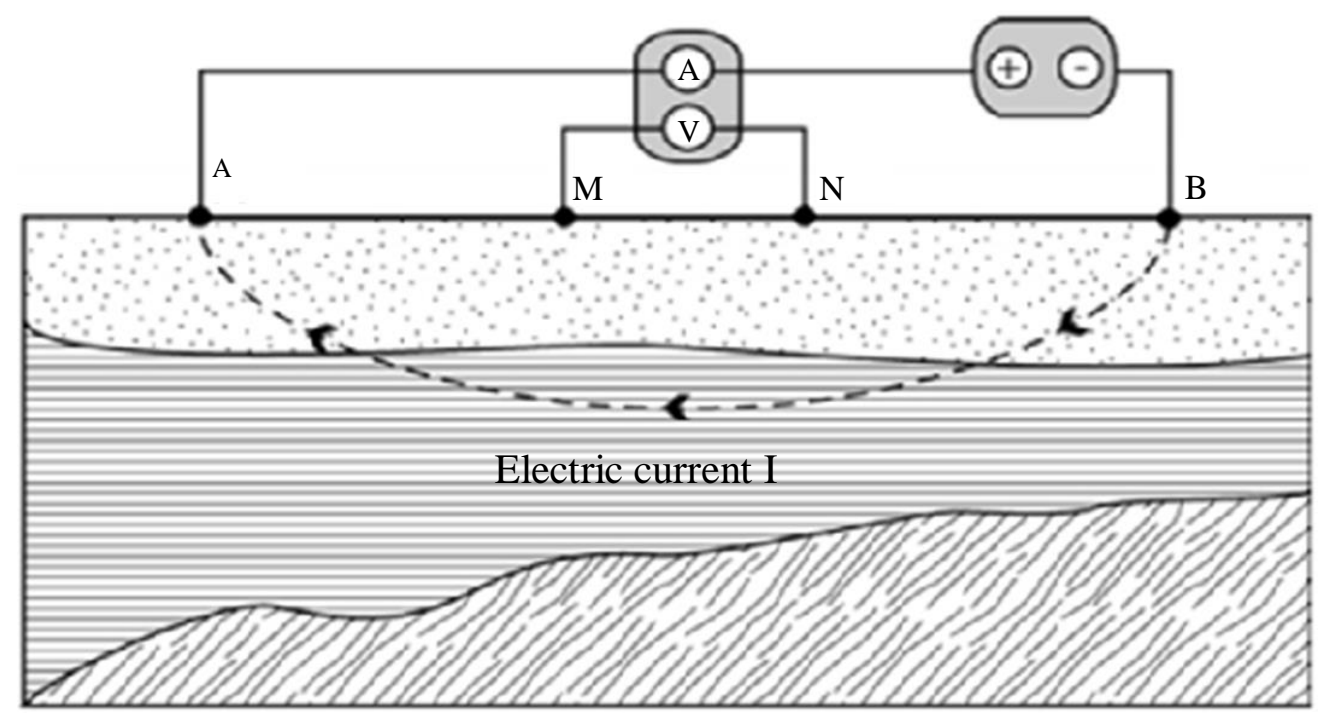

Fig. 4: Representation of the schlumberger type device 


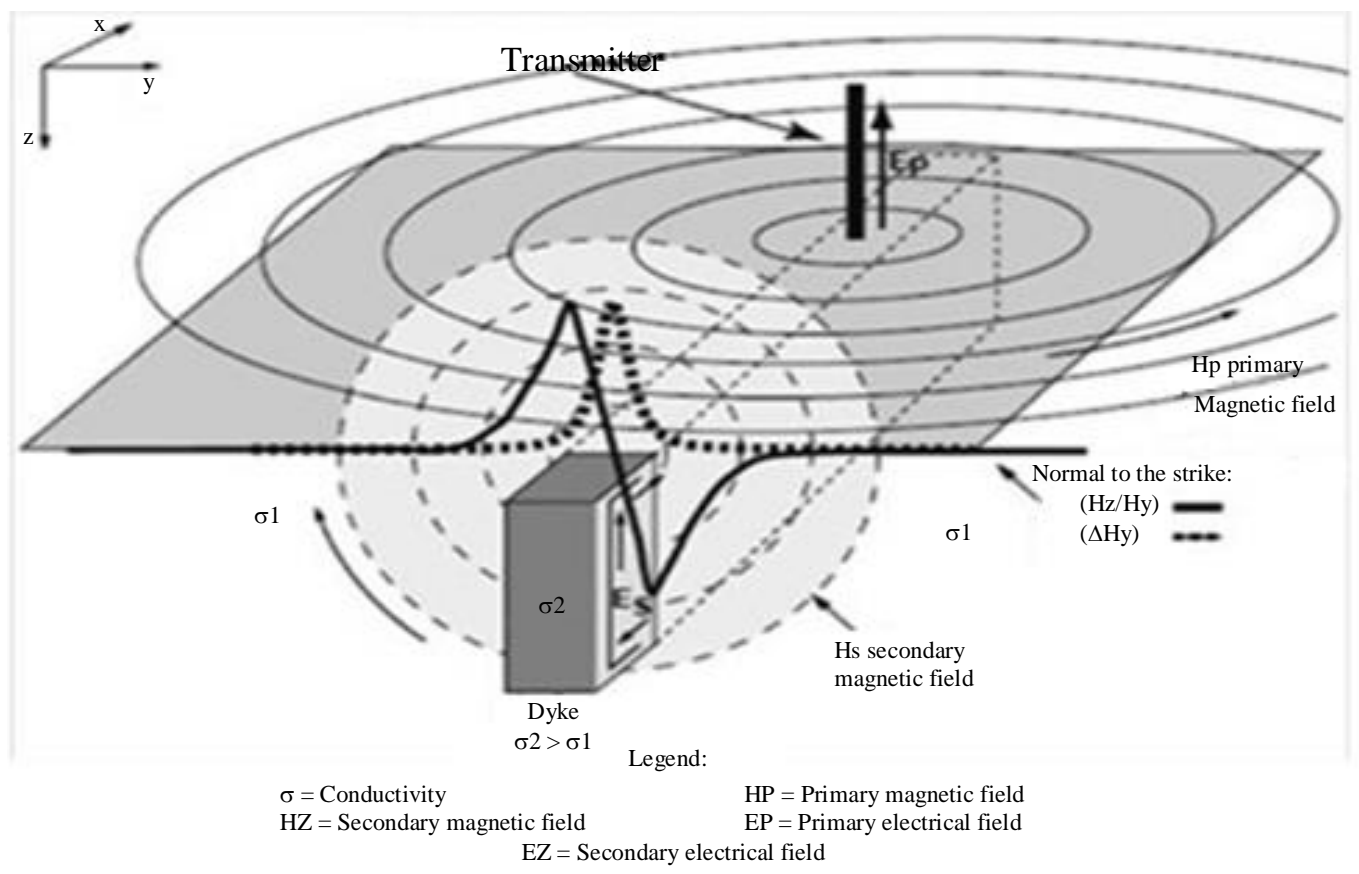

Fig. 5: Field components of VLF field from transmitter at Remote Distance (Ezepue, 1984)

For our measurements, in one hand, the Karous and Hjelt (KH) filter has been applied to the real component. This filter permits the draw of apparent current density cross-sections, which show the response of the conductor in depth (Karous and Hjelt, 1983). Qualitatively, it is possible to discriminate between conductive and resistive structures using apparent current density cross-section (Karous and Hjelt, 1977), where a high positive value corresponds to conductive structure and low negative values are related to resistive one (Benson et al., 1997; Sharma and Baranwal, 2005), In the other hand, the Fraser filter has been applied to the real component too and presented in the form of a contour map. Therefore, the filtered real component will always show a positive peak above an anomalous zone (Fraser, 1969). In order to perform KarousHjelt and Fraser filtering on VLF EM data, the software KHFFILT is used in the interpretation of the measurements along VLF traverses.

\section{Results}

In order to obtain better recognition of the study site, we used two geophysical techniques; the method of electrical and electromagnetic exploration. In fact, two Schlumberger-type electrical soundings were carried out $(A B=600 \mathrm{~m}$ long $)$ and six electromagnetic profiles (Fig. 6).

\section{Electrical Prospecting}

The electrical survey $\mathrm{N}^{\circ} 1$ is carried out next to the village of Douira on the left bank of the national road
$\mathrm{N}^{\circ} 13$ (about $100 \mathrm{~m}$ ) which leads to Erfoud. Its direction is N-S (Fig. 7a). While the survey $\mathrm{N}^{\circ} 2$ was carried out at $250 \mathrm{~m}$ from the source of Ain El Atti in direction NW-SE Fig. 7b.

\section{Electromagnetic Prospecting}

We focus on the analysis of positive Karous-Hjelt anomalies, for semi-quantitative interpretation and visualization of the target. For the data filtered by KH, the cross-sectional curves of the apparent current density were produced (Figs. 9 to 11). Here, the traces $\mathrm{KH}$ are represented for three types of lines: 2, 3 and 4.

\section{Discussion}

The survey in Fig. 6 suggests the presence of a conglomerate formation with gravel on the surface, of resistivity $\rho=2000 \mathrm{Ohm} . \mathrm{m}$ and of thickness $1 \mathrm{~m}$. The latter rests on a formation of weathered sandstone with clays, of resistivity $\rho=300 \mathrm{Ohm}-\mathrm{m}$ and thickness $7 \mathrm{~m}$, which overcomes a formation of limestone's of resistivity $\rho=3060 \mathrm{Ohm}-\mathrm{m}$ and thickness $64 \mathrm{~m}$. In depth, we find sandy sandstones with clays of resistivity $\rho=750$ Ohm-m (Fig. 8a). For the survey in Fig. 7b highlights the sands and gravels in surface (resistivity $\rho$ $=300$ Ohm $-\mathrm{m}$ and thickness $2.6 \mathrm{~m}$ ) overcome a claymarly formation with resistivity $\rho=9 \mathrm{Ohm}-\mathrm{m}$ and thickness $16 \mathrm{~m}$, which rests on the sandstones $(\rho=270$ Ohm-m and thickness $16 \mathrm{~m}$ ). At the base, we find a marl formation of resistivity $8 \mathrm{Ohm}-\mathrm{m}$ (Fig. $8 \mathrm{~b}$ ). 


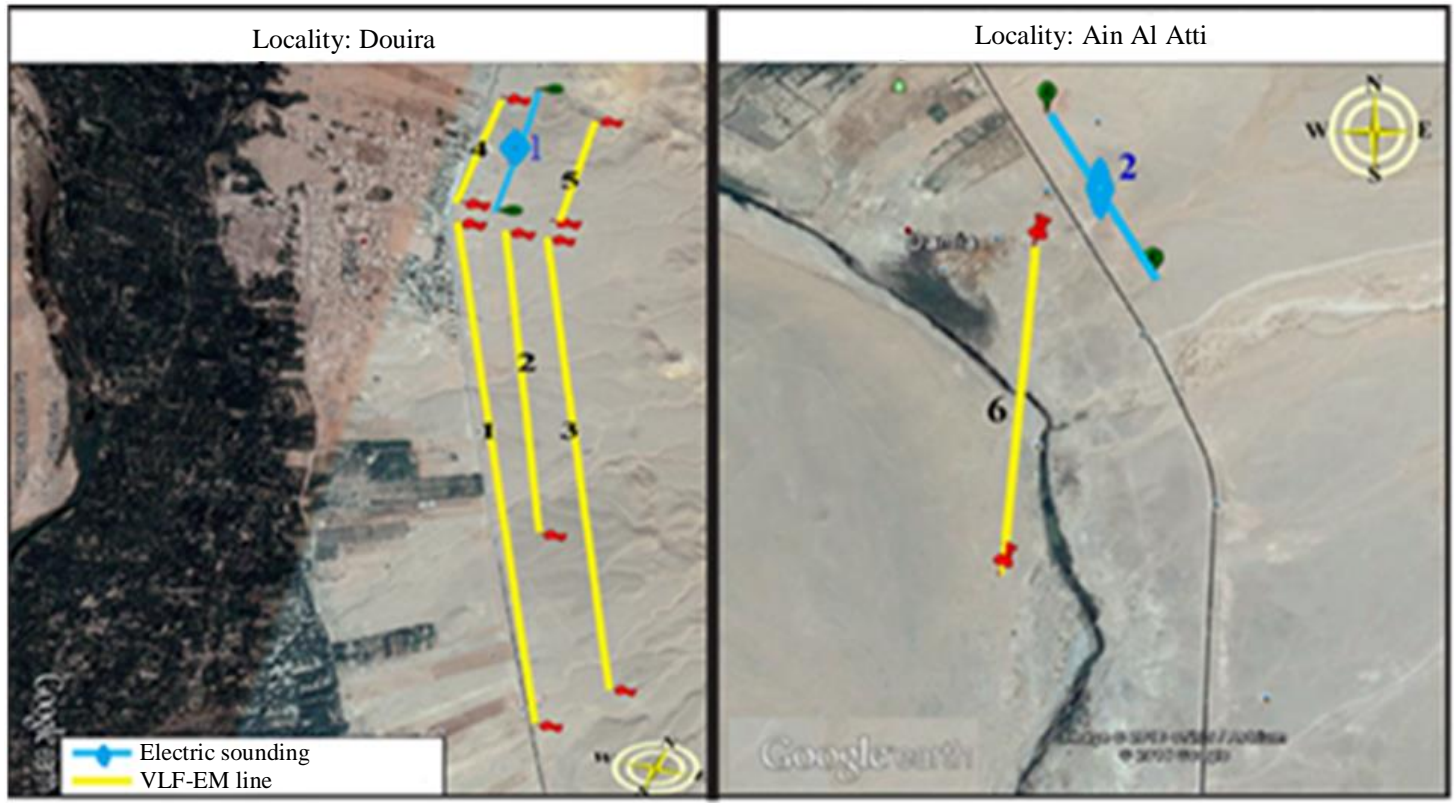

Fig. 6: Location of electrical and electromagnetic surveys

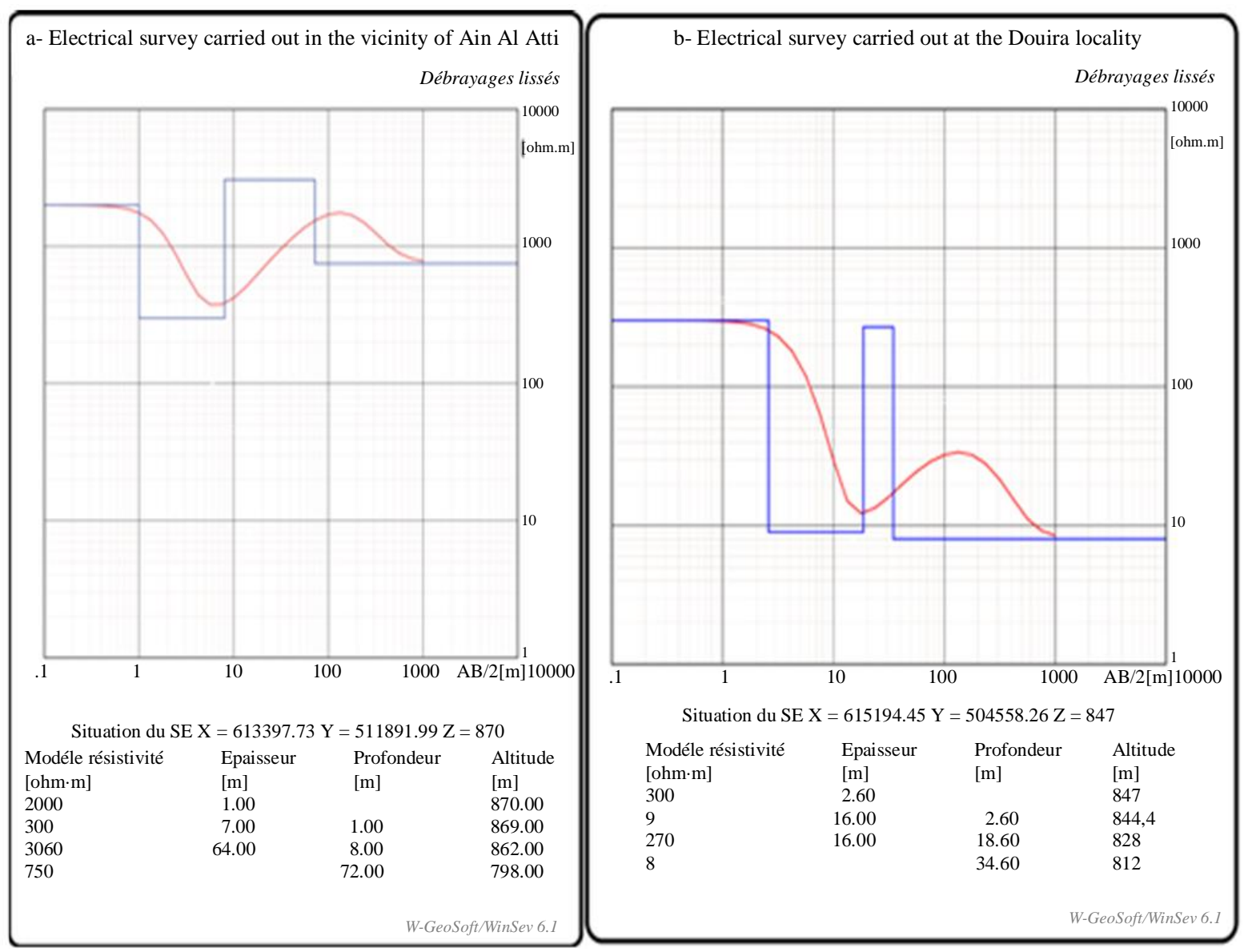

Fig. 7: Electrical survey: a- Douira, b- Ain Al Atti 

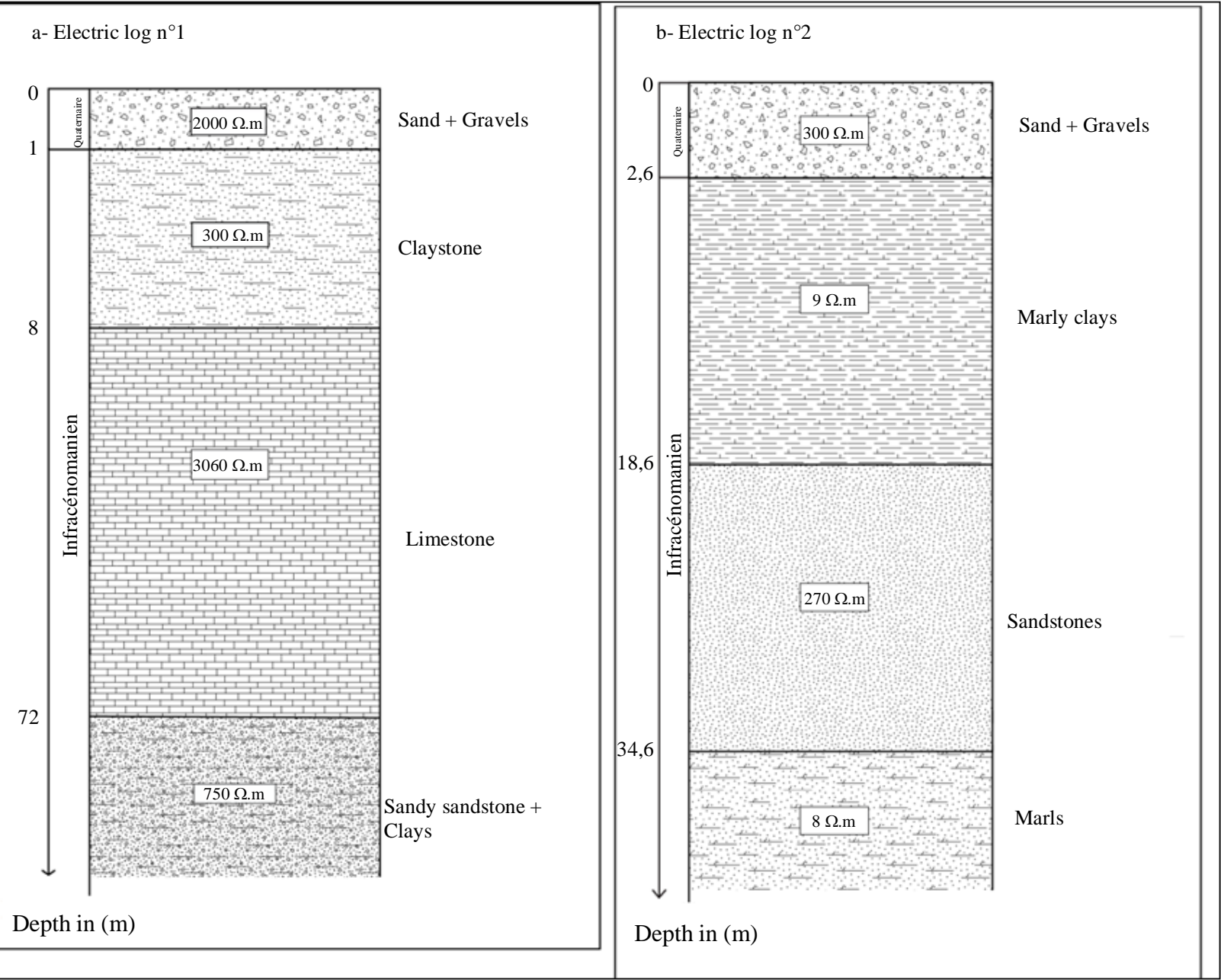

Fig. 8: Synthetic electric logs: a- Survey carried out in Douira, b- Survey carried out in Ain Al Atti

Taking into account the electrical logs (Fig. 8a and $8 b$ ), we observe that for the upper part of the field investigated, the formations encountered at Douira are relatively the same encountered at Ain Al Atti, however in depth we find a variation of facies (gray and limestone at the level of Douira and the marls at the level of Ain Al Atti), these marly formations with intercalation of gypsum encountered in depth, caused a significant decrease in the electrical resistivity in the vicinity of Ain Al Atti.

The line (Fig. 8a) represents the variation of the apparent section of the current density as a function of the distance, along line 2 . The plot shows a prominent positive response between $900-1000 \mathrm{~m}$, from the start of the profile, corresponding to a conductive ax, resulting in a fracture zone at a depth ranging from the surface to $170 \mathrm{~m}$. The results of line 3 are represented as a cross section of apparent current density in Fig. 9a.
The plot reveals a positive anomaly linked to the presence of a conductive target at $1580 \mathrm{~m}$ from the start of the profile. It is interpreted as a fracture zone at a depth ranging from surface to $140 \mathrm{~m}$. the KH Filtering data from the rest of these lines does not show any pronounced anomalies. The result of line 4 (Fig. 10a) suggests the presence of a conductive anomaly at a distance of $350 \mathrm{~m}$ which corresponds to the same fractured zone. The filtered Fraser data reveals the presence of anomalies which are located and correlated to the anomalies obtained by Karous Hjelt filtration. Three positive anomalies were distinguished, where the apex of the anomalies was observed at locations L2 (Fig. 8b), L3 (Fig. 9b) and L4 (Fig. 10b). These are linked to the presence of conductive structures, interpreted as fracture zones. This fracture has a major NW-SE direction which confirms the work carried out at the level of the locality Zaouia Jdida by Ait (Bahammou et al., 2019) is schematized on the model of Fig. 12. 
Dakir Ibrahim et al. / Current Research in Geoscience 2020, Volume 10: 16.26 DOI: 10.3844/ajgsp.2020.16.26

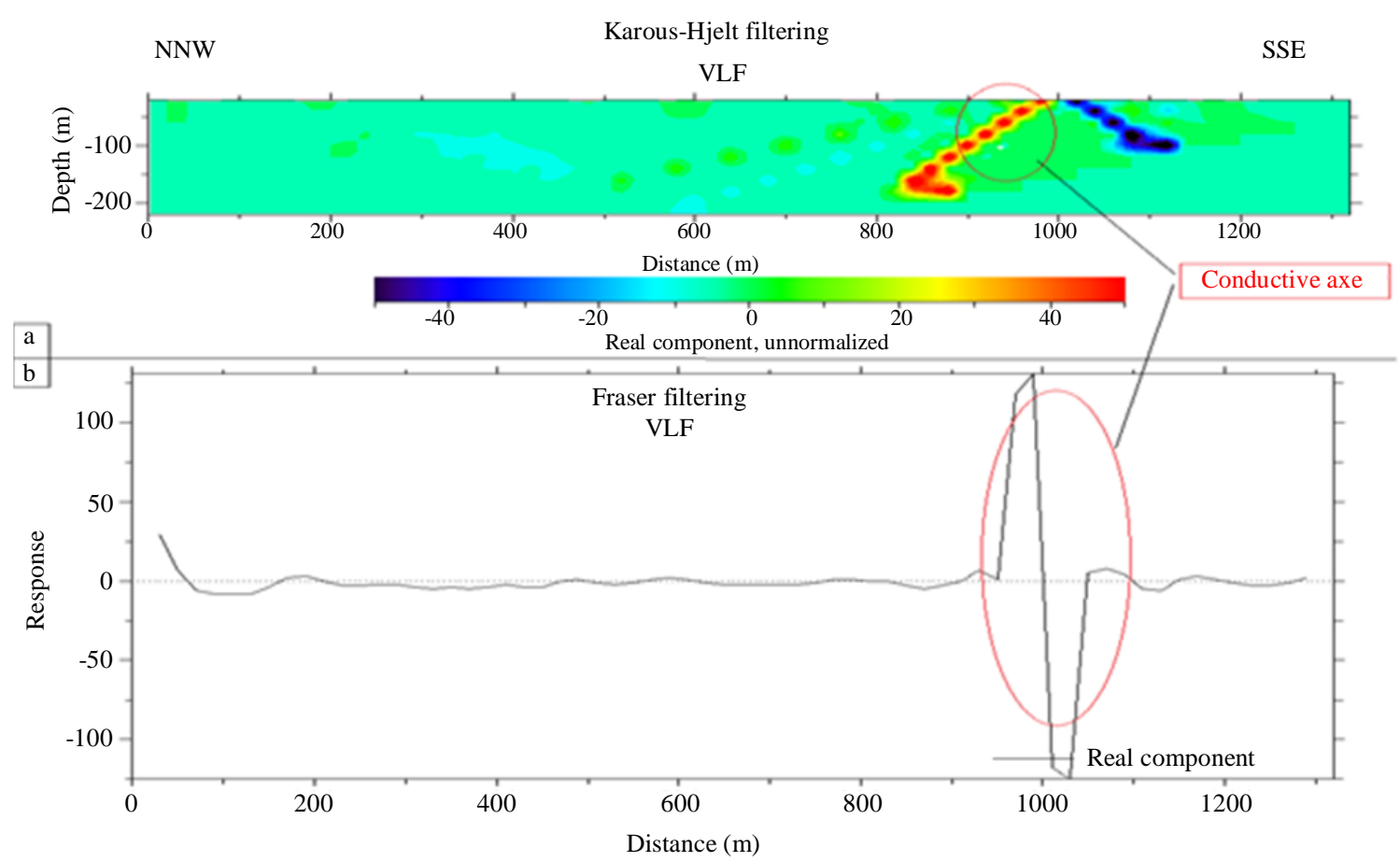

Fig. 9: Electromagnetic VLF-L2: a- apparent current density cross section, b- fraser filtering

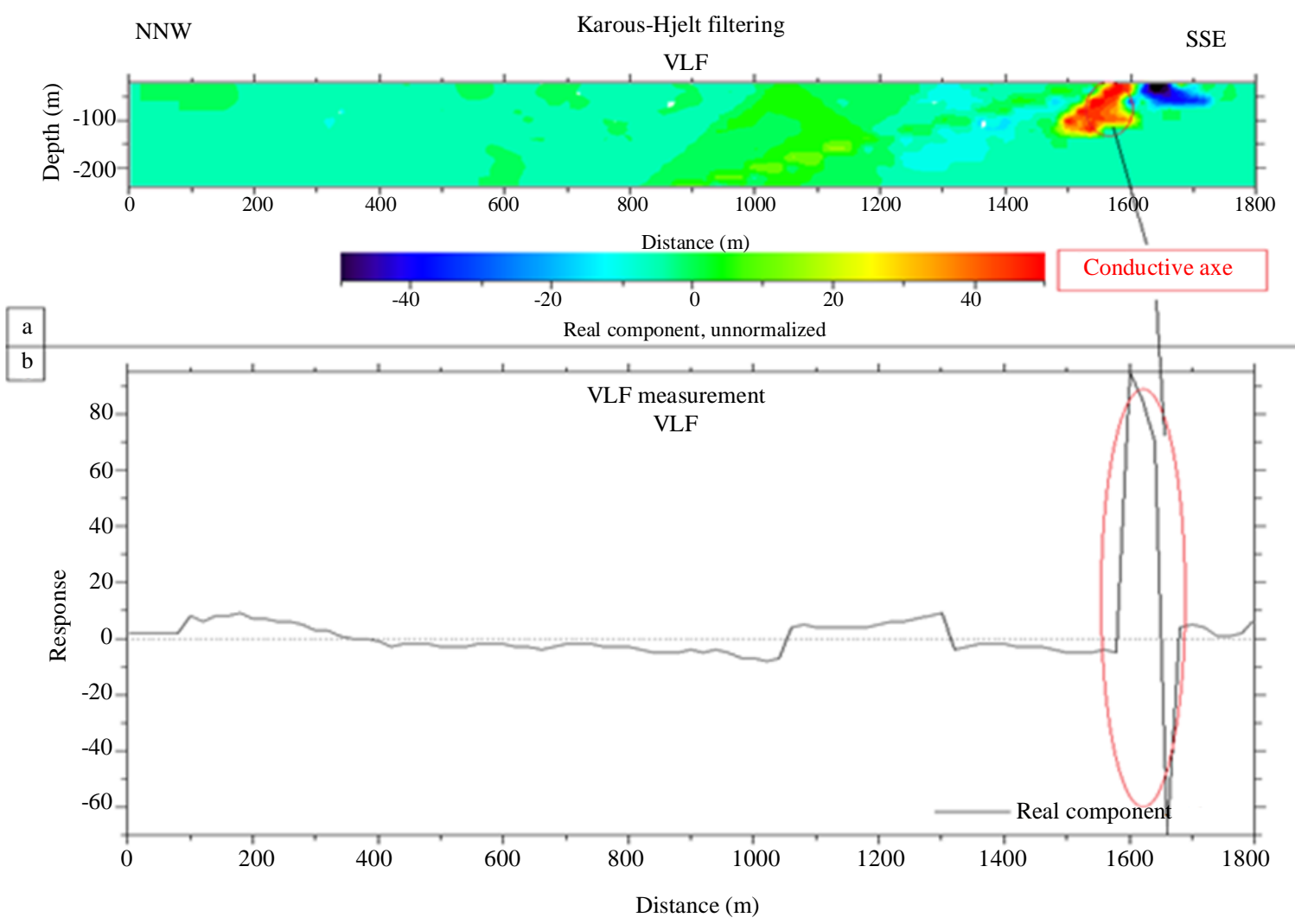

Fig. 10: Electromagnetic VLF-L3: A- apparent current density cross section, b- fraser filtering 
Dakir Ibrahim et al. / Current Research in Geoscience 2020, Volume 10: 16.26 DOI: 10.3844/ajgsp.2020.16.26



Fig. 11: Electromagnetic VLF-L4: a- apparent curent density cross section, b- fraser filtering

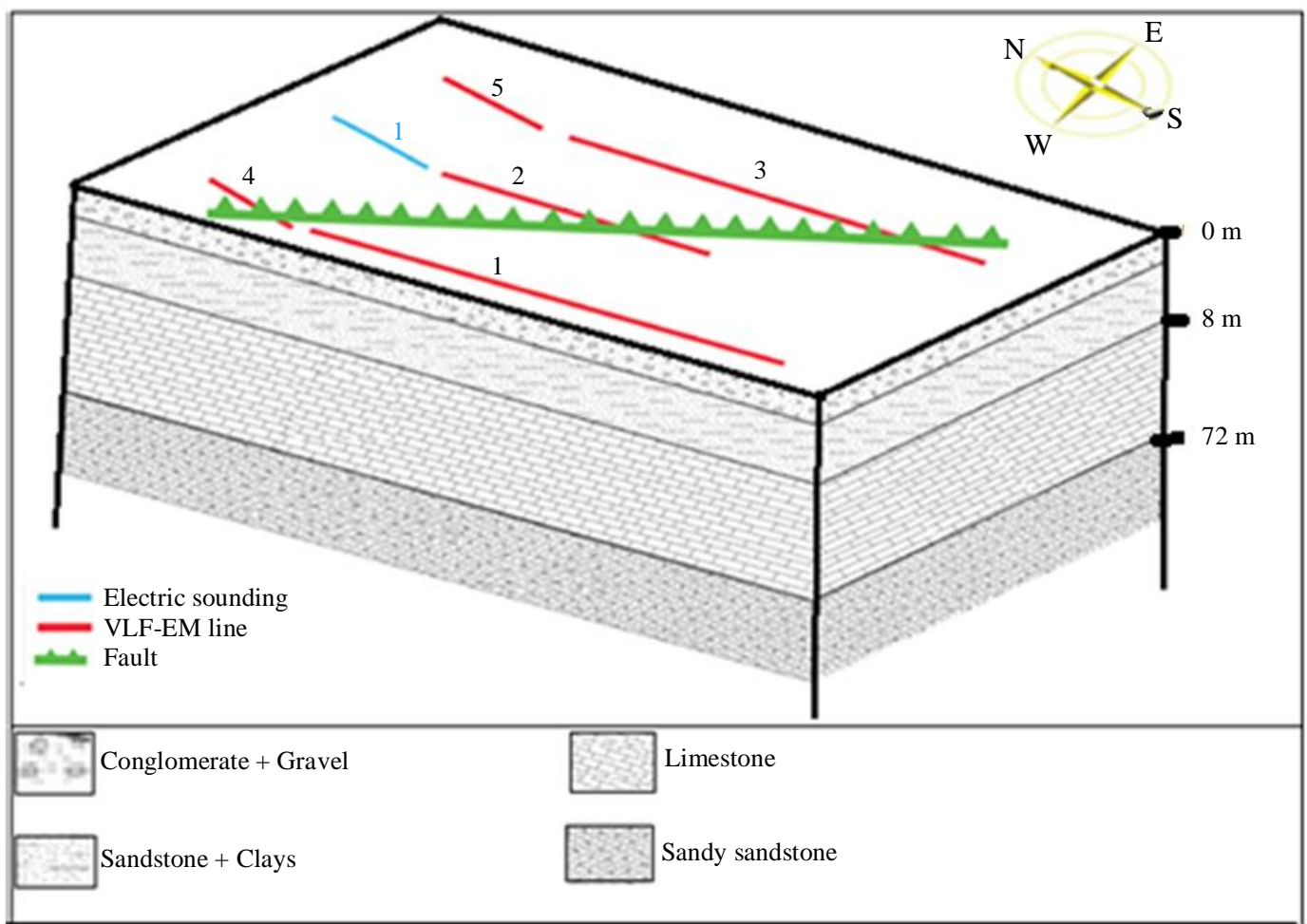

Fig. 12: Schematic model of the location of the fracturing zone 


\section{Conclusion}

In this article, we have contributed to the litho-structural study at the level of the locality of Douira and near the artesian source of Ain Al Atti, by combining the electrical technique and the very low frequency electromagnetic method. The results of the electrical soundings showed the presence of very conductive grounds in the vicinity of the source which is due to the capillary rise of the salinity coming from marly formations with gypsum intercalations in depth. Data filtered by VLF revealed the presence of a fracture anomaly which reached $150 \mathrm{~m}$ in depth and which is oriented NW-SE. The identified fracture anomaly constitutes the potential groundwater circulation area that led to the supply of the Ain Al Atti source.

Given the importance of the results obtained at the level of the prospected area, it is advisable to carry out other electromagnetic profiles and electrical trails in the northern part of the locality of Douira and to carry out a mechanical survey at the level of these conductive anomalies. To block the loss of salt water from the Ain Al Atti source.

\section{Acknowledgement}

The authors are sincerly grateful to the Faculty of Science and Technology Errachidia (FSTE) for proveding the geophysical machines used in this study.

\section{Author's Contributions}

Dakir Ibrahim: I carried out the geophysical measurements, I contributed to the interpretation of the data, the writing of the article.

Benamara Ahmed: I am the professional supervisor of Mr. DAKIR. I helped the main author with the interpretation of geophysical data.

Aassoumi Habiba: I am the administrative supervisor of Mr. DAKIR. Helped the main author with manuscript writing and translation.

Ouallali Abdessalam: I contributed to the field level; we carried out together several geophysical companies.

Ait Bahammou Youssef: I contributed to the field level; we carried out together several geophysical companies.

\section{Ethics}

This article is original and contains unpublished data. The corresponding author confirms that all of the other authors have read and approved the manuscript and no ethical issues involved

\section{Data Availability}

The data used to support the findings of this study are available from the corresponding author upon request.

\section{References}

Amharref, M. (1991). Contribution à l'étude hydrogéologique de la vallée du $\mathrm{Ziz}$ (province d'Errachidia Sud-Est du Maroc): Incidences respectives de la sécheresse et du Barrage Hassan Addakhil sur les ressources à l'aval (Doctoral dissertation, Besançon).

Ammary, B. (2007). Etude géochimique et isotopique des principaux aquifères $\mathrm{du}$ bassin Crétacé d'Errachidia et de la plaine de Tafilalet.

Bahammou, Y. A., Benamara, A., Ammar, A., \& Dakir, I. (2019). Fracture zones detection for groundwater exploration integrating Resistivity Profiling and Very Low Frequency electromagnetic methods (Errachidia basin, Morocco). Contributions to Geophysics and Geodesy, 49(2), 181-194.

Benson, A. K., Payne, K. L., \& Stubben, M. A. (1997). Mapping groundwater contamination using dc resistivity and VLF geophysical methods-A case study. Geophysics, 62(1), 80-86.

Choubert, G. (1948). Essai sur la paléogéographie du Mésocrétacé marocain. Volume jubilaire de la Société des Sciences Naturelles du Maroc, 1920210(1945), 307-329.

Choubert, G., \& Faure-Muret, A. (1960). Evolution du domaine atlasique marocain depuis les temps paléozoïques. Mémoire hors-série-Société géologique de France, (1), 447-527.

Eze, C. L., Mamah, L. I., \& Israel-Cookey, C. (2004). Very low frequency electromagnetic (VLF-EM) response from a lead sulphide lode in the Abakaliki lead/zinc field, Nigeria. International journal of applied earth observation and geoinformation, 5(2), 159-163.

Ezepue, M. C. (1984). The geologic setting of lead-zinc deposits at Ishiagu, southeastern Nigeria. Journal of African Earth Sciences (1983), 2(2), 97-101.

Fraser, D. C. (1969). Contouring of VLF-EM data. Geophysics, 34(6), 958-967.

Karous, M., \& Hjelt, S. E. (1977). Determination of apparent current density from VLF measurements: Report. Department of Geophysics, University of Oulu, Finland, Contribution, 89, 19.

Karous, M., \& Hjelt, S. E. (1983). Linear filtering of VLF dip-angle measurements. Geophysical prospecting, 31(5), 782-794.

Kaya, M. A., Özürlan, G., \& Şengül, E. (2007). Delineation of soil and groundwater contamination using geophysical methods at a waste disposal site in Çanakkale, Turkey. Environmental monitoring and assessment, 135(1-3), 441-446.

Margat, J. (1977). Etude hydrogéologique du bassin Quaternaire de Tafilalet. Ressources en Eau du Maroc, p310-380. 
McNeill, J. D., \& Labson, V. F. (1991). Geological mapping using VLF radio fields. In Electromagnetic Methods in Applied Geophysics: Volume 2, Application, Parts A and B (pp. 521-640). Society of Exploration Geophysicists.

Reinhard, K. (Ed.). (2006). Groundwater Geophysics: A Tool for Hidrogeology. Springer.
Saydam, A. S. (1981). Very low-frequency electromagnetic interpretation using tilt angle and ellipticity measurements. Geophysics, 46(11), 1594-1605.

Sharma, S. P., \& Baranwal, V. C. (2005). Delineation of groundwater-bearing fracture zones in a hard rock area integrating very low frequency electromagnetic and resistivity data. Journal of Applied geophysics, 57(2), 155-166. 